Original Article

\title{
Hubungan Lama Penggunaan Kontrasepsi Hormonal terhadap Skor Inner Scan Body Composition Monitor pada Wanita Usia Subur
}

\section{The Relationship of Long Use of Hormonal Contraception on Inner Scan Body Composition Monitor Scores in Women of Childbearing Age}

\author{
Hasriani Saleng*, Rahayu Eryanti K, Jumrah Sudirman \\ Prodi Kebidanan \& Profesi Bidan, Fakultas Keperawatan \& Kebidanan Universitas \\ Megarezky, Indonesia \\ (*hasriani.asni863@gmail.com,081241830002)
}

\begin{abstract}
ABSTRAK
Osteoporosis merupakan masalah kesehatan dunia dimana saat ini diderita oleh kelompok usia yang lebih muda. Kepadatan mineral tulang merupakan salah satu jenis parameter dalam mengukur status osteoporosis. Semakin rendah kepadatan mineral tulang maka semakin besar risiko osteoporosis. Salah satu faktor risiko rendahnya kepadatan mineral tulang adalah jenis dan lama penggunaan kontrasepsi hormonal. Penelitian ini bertujuan untuk mengetahui hubungan penggunaan kontrasepsi hormonal dengan skor Inner Scan Body Composition Monitor dalam kepadatan tulang wanita usia subur. Metode penelitian yang digunakan adalah kuantitatif dengan desain cross sectional study, sampel penelitian 46 akseptor dengan teknik sampling yaitu Purposive sampling. Analisis data menggunakan Mann Whitney. Hasil penelitian didapatkanhasil untuk Skor Inner Scan Body Composition Monitor pada akseptor baru dengan nilai mean \pm SD yaitu $2.1429 \pm 0.45779$ dan nilai min-max adalah $1.40-3.00$. Sementara pada akseptor lama dengan nilai mean \pm SD yaitu $2.3840 \pm 0.38479$ dan nilai min-max adalah 1.50 - 3.20. Pada analisis Bivariat didapatkannilai $\mathrm{p}=0.086>0,05$, hal ini menunjukkan tidak Ada hubungan antara lama penggunaan kontrasepsi hormonal dengan skor inner scan bodyatau kepadatan tulang pada akseptor kontrasepsi hormonal. Kesimpulan, lama penggunaan kontrasepsi hormonal tidak mempengaruhi skor Inner Scan Body Composition Monitor pada kepadatan tulang akseptor di Wilayah Kota Makassar.
\end{abstract}

Kata kunci : Akseptor, Kepadatan Tulang, Kontrasepsi Hormonal, Skor Inner Scan Body

\section{ABSTRACT}

Osteoporosis is a global health problem which currently affects younger age groups. Bone mineral density is one type of parameter in measuring osteoporosis status. The lower the bone mineral density, the greater the risk of osteoporosis. One of the risk factors for low bone mineral density is the type and duration of use of hormonal contraception.. This study aims to determine the relationship between the use of hormonal contraception and the Inner Scan Body Composition Monitor score in the bone density of women of childbearing age. The research method used is quantitative with a cross sectional study design, the research sample is 46 acceptors with a sampling technique that is purposive sampling. Data analysis using Mann Whitney. The results showed that the score for the Inner Scan Body Composition Monitor on new acceptors with a mean $\pm S D$ value of $2.1429 \pm 0.45779$ and a min-max value of $1.40-3.00$. Meanwhile, for the old acceptors, the mean $\pm S D$ is $2.3840 \pm 0.38479$ and the minmax value is $1.50-3.20$. In the Bivariate analysis, the $p$ value $=0.086>0.05$, this indicates that there is no relationship between the duration of hormonal contraceptive use and the inner scan body score or bone density of hormonal contraceptive acceptors. In conclusion, the duration of using hormonal contraception does not affect the score of the Inner Scan Body Composition Monitor on bone density of acceptors in the Makassar City Region.

Keywords : Acceptor, Bone Density, Hormonal Contraception, Inner Scan Body Score

https://doi.org/10.33860/jik.v15i3.483 


\section{PENDAHULUAN}

Osteoporosis merupakan masalah kesehatan dunia (global issue). Hal ini dikarenakan meskipun prevalensi osteoporosis tertinggi di derita oleh wanita usia lanjut, namun berdasarkan penelitian ditemukan bahwa prevalensi kejadian osteoporosis pada pria meningkat dibandingkan sebelumnya. Selain itu diketahui bahwa osteoporosis kini diderita pada kelompok usia yang lebih muda. Penyakit kerapuhan tulang melanda seluruh dunia dan telah melumpuhkan jutaan orang(1) WHO tahun 2007 menyatakan penyakit osteoporosis sudah saatnya mendapat perhatian yang lebih serius. Sebagian besar masyarakat masih percaya bahwa penyakit tersebut merupakan sesuatu yang tidak perlu dikhawatirkan karena dianggap suatu keadaan yang biasa terjadi pada usia lanjut.

Penelitian yang dilakukan oleh puslitbang gizi kementerian kesehatan RI didapatkan angka prevalensi osteopenia sebesar $41,7 \%$ dan osteoporosis $10,7 \%$. 2 dari 5 penduduk Indonesia memiliki resiko mengalami osteoporosis. Angka kejadian osteopenia pada laki-laki ditemukan lebih rendah dibandingkan dengan wanita usia diatas 50 tahun. Prevalensi osteoporosis pada wanita asia telah berhasil menurun $10,1 \%$ akan tetapi angka ini masih dalam kategori tinggi jika dibandingkan dengan Negara asia tenggara lainnya $(2,3)$

Kepadatan mineral tulang adalah salah satu parameter untuk mengukur status osteoporosis. Semakin rendah kepadatan mineral tulang maka semakin besar risiko osteoporosis. Salah satu faktor risiko rendahnya kepadatan mineral tulang adalah jenis dan lama penggunaan kontrasepsi hormonal Berkurangnya hormon estrogen mengakibatkan kaum perempuan memiliki resiko lebih tinggi terkena osteoporosis terutama pada masa menopause karena hormon estrogen menurun mengakibatkan kecepatan penurunan masa tulang. Pengguna suntik DMPA (Depo Medroxil Progestin Asetatat) memiliki prosentase yang sangat tinggi(4) Di Indonesia akseptor KB Suntik DMPA memiliki prosentase terbesar yaitu $49,93 \%$ untuk akseptor baru dan $47,78 \%$ untuk akseptor lama. Di Sulawesi Selatan prosentase penggunaan kontrasepsi suntik DMPA sebesar $57,19 \%$ dan di beberapa kabupaten sebesar 70,2\%. Besarnya penggunaan kontrasepsi ini dilatarbelakangi oleh berbagai alasan, diantaraya alasan biaya yang cukup murah, tidak sakit dan mudah penggunaan kontrasepsi, serta tidak menakutkan seperti pemasangan IUD ataupun kotrasepsi mantap(5)

Penelitian ini bertujuan untuk mengetahui hubungan penggunaan kontrasepsi hormonal dengan skor Inner Scan Body Composition Monitor dalam kepadatan tulang wanita usia subur..

\section{METODE PENELITIAN}

Penelitian ini adalah penelitian kuantitatif dengan cross sectional study(6) Populasi dalam penelitian ini seluruh akseptor kontrasepsi di Wilayah Kota Makassar. Sampel dalam penelitian ini adalah seluruh akseptor $\mathrm{kb}$ hormonal di wilayah kota Makassar sebanyak 46 orang. Teknik pengambilan sampel dilakukan dengan cara purposive sampling.

Pengumpulan data yaitu data Karakteristik Responden Kuesioner tentang karakteristik responden berisi nama,usia, riwayat kelahiran dan riwayat penyakit lalu. Lembar Observasi, yang merupakan sebuah format yang berisi hasil pemeriksaan sebelum dan setelah penggunaan kontrasepsi. Selannjutnya data dianalisis bivariate menggunakan uji Mann withney.

\section{HASIL}

Berdasarkan tabel 1 menunjukkan kelompok umur $<35$ tahun didapatkan 34 orang (73,9\%), kelompok umur $\geq 35$ tahun didapatkan 12 orang $(26,1 \%)$, pendidikan tinggi sebanyak 4 orang $(8,7 \%)$, dan yang pendidikan rendah didapatkan sebanyak 42 orang $(91,3 \%)$, Ibu dengan status tidak bekerja $(93,5 \%)$ dan yang bekerja (6,5\%). Ibu dengan jumlah kehamilan (paritas) $<3$ didapatkan sebanyak 37 orang $(80,4 \%)$, dan $\geq 3$ terdapat 9 orang $(19,6 \%)$, kemudian terdapat akseptor lama 21 orang (45,7\%), akseptor baru 25 orang $(54,3 \%)$.

Pada tabel 2 Distribusi skor inner body composition monitor berdasarkan umur didapatkan ibu dengan massa tulang tergolong normal pada usia $<35$ tahun 8 orang $(17,4 \%)$ dan ibu dengan usia $\geq 35$ tahun 7 orang $(15,2 \%)$. Ibu dengan status pendidikan tinggi memiliki massa tulang yang tidak normal sebanyak 4 orang $(8,7 \%)$ sedangkan ibu dengan pendidikan yang masih rendah memiliki massa tulang yang tidak normal sebanyak 27 orang $(58,7 \%)$. Kemudian ibu dengan status tidak bekerja didapatkan massa tulang yang tidak normal 
sebanyak 28 orang $(60,9 \%)$ sedangkan pada ibu yang bekerja didapatkan hanya sebanyak 3 orang $(6,5 \%)$. Ibu dengan jumlah kehamilan $<3$ memiliki massa tulang normal 11 orang $(23,9 \%)$ dan ibu dengan jumlah kehamilan $\geq 3$ sebanyak 4 orang $(8,7 \%)$.

Tabel 3 didapatkan hasil untuk Skor Inner Scan Body Composition Monitor pada akseptor baru dengan nilai mean \pm SD yaitu $2.1429 \pm$ 0.45779 dan nilai min-max adalah $1.40-3.00$. Sementara pada akseptor lama dengan nilai mean \pm SD yaitu $2.3840 \pm 0.38479$ dan nilai minmax adalah 1.50 - 3.20. menunjukkan bahwa hasil analisis data menggunakan uji Mann Withney didapatkan nilai $p=0.086 a>0.05$ yang artinya tidak ada hubungan antara lama penggunaan $\mathrm{kb}$ hormonal dengan kadar mineral tulang.
Tabel 1 Distribusi Frekuensi Karakteristik Responden

\begin{tabular}{lll}
\hline Variabel & $\mathbf{N}$ & $\mathbf{\%}$ \\
\hline Umur & & \\
$<35$ tahun & 34 & 73,9 \\
$\begin{array}{l}\geq 35 \text { tahun } \\
\text { Pendidikan }\end{array}$ & 12 & 26,1 \\
$\begin{array}{l}\text { Tinggi } \\
\text { Rendah }\end{array}$ & 4 & 8,7 \\
Pekerjaan & 42 & 91,3 \\
Tdk bekerja & 43 & 93,5 \\
$\begin{array}{l}\text { Bekerja } \\
\text { Paritas }\end{array}$ & 3 & 6,5 \\
$<3$ & 37 & 80.4 \\
$\geq 3$ & 9 & 19.6 \\
Lama Penggunaan & & \\
Lama & 21 & 45,7 \\
Baru & 25 & 54,3 \\
Total & 46 & 100 \\
\hline
\end{tabular}

Tabel 2 Distribusi Skor Inner Scan Body Composition Monitor

\begin{tabular}{|c|c|c|c|c|c|}
\hline \multirow[t]{2}{*}{ Variabel } & \multicolumn{4}{|c|}{ Massa Tulang } & \multirow[t]{2}{*}{ Total } \\
\hline & Normal & & & & \\
\hline \multicolumn{6}{|l|}{ Umur } \\
\hline$<35$ tahun & 8 & 17.4 & 26 & 56.5 & 34 \\
\hline$\geq 35$ tahun & 7 & 15,2 & 5 & 10,9 & 12 \\
\hline \multicolumn{6}{|l|}{ Pendidikan } \\
\hline Tinggi & 0 & 0 & 4 & 8,7 & 4 \\
\hline Rendah & 15 & 32,6 & 27 & 58,7 & 42 \\
\hline \multicolumn{6}{|l|}{ Pekerjaan } \\
\hline Tdk bekerja & 15 & 32,6 & 28 & 60,9 & 43 \\
\hline Bekerja & 0 & 0 & 3 & 6,5 & 3 \\
\hline \multicolumn{6}{|l|}{ Paritas } \\
\hline$<3$ & 11 & 23,9 & 26 & 56,5 & 37 \\
\hline$\geq 3$ & 4 & 8,7 & 5 & 10,9 & 9 \\
\hline
\end{tabular}

Tabel 3 Analisa Lama Penggunaan KB Hormonal dengan Kadar Mineral Tulang Ibu

\begin{tabular}{lllll}
\hline Lama Penggunaan & N & Mean \pm SD & Min-Mix & Nilai p \\
\hline Baru & 21 & $2.1429 \pm 0.45779$ & $1.40-3.00$ & 0.086 \\
Lama & 25 & $2.3840 \pm 0.38479$ & $1.50-3.20$ & \\
Total & 46 & & & \\
\hline
\end{tabular}

\section{PEMBAHSAN}

Berdasarkan tabel 2 dari 46 responden akseptor kb hormonal (100\%). Pengguna baru didapatkan mean rank 19.81 sedangkan pada kelompok pengguna lama didapatkan 26.60 dengan hasil uji analisis menggunakan Mann Withney didapatkan nilai $\mathrm{p}=0.086 \mathrm{a}>0.05$ sehingga tidak ada hubungan antara lama penggunaan $\mathrm{kb}$ hormonal dengan kadar massa tulang pada ibu akseptor kb baik pengguna lama maupun baru. Hasil penelitian ini berbeda dengan hasil penelitian Peni, dkk (2015) dimana nilai $P$ hitung $=0,773$ dengan $\mathrm{d}=10 \%$. Oleh karena $P$ hitung $>P$ tabel $(0,773>0,267)$ maka H0 ditolak artinya ada hubungan antara lama penggunaan KB suntik DMPA dengan densitas tulang di RW 3 Lesanpuro wilayah kerja Puskesmas Gribig Kota Malang(7)

Alat kontrasepsi hormonal terdiri dari beberapa jenis, salah satunya merupakan $\mathrm{kb}$ pil.Pil sebagai alat kontrsepsi hormonal yang paling mudah dalam penggunaannya yakni 
dengan cara dikonsumsi secara oral atau diminum setiap malam sebelum tidur oleh tiap akseptor(2,8). Kontrasepsi pil merupakan alat kontrasepsi yang cukup diminati bagi ibu yang ingin menjadi akseptor kb akan tetapi dengan berbagai alasan dari tiap individu sehingga menjatuhkan pilihan pada kb pil sebagai alat kontrasepsi yang ingin digunakan.Kemudian alat kontrasepsi hormonal lainnya yakni kontrasepsi suntik yang merupakan kontrasepsi hormonal terdiri dari 2 pilihan masa suntik yakni suntik 1 bulan dan 3 bulan. Akseptor kb suntik secara berkala mendatangi fasilitas kesehatan untuk diberikan suntikan kb sesuai dengan keinginan ibu sebagai akseptor dengan cara disuntikkan secara intramuskuler(7). Adapun kontrasepsi hormonal yang lain yaitu implant menjadi salah satu dari kontrasepsi hormonal yang angka akseptornya cukup tinggi. Diberikan dengan cara membuat insisi pada lengan atas bagian dalam kemudian dimasukkan kebawah kulit dan bekerja dengan pelepasan hormone progestin untuk menekan terjadinya $(8,9)$

Kadar massa tulang setiap individu dipengaruhi oleh beberapa faktor yakni aktivitas fisik seperti olahraga, kemudian life style, asupan nutrisi dari makanan yang mengandung vitamin $\mathrm{D}$ dan zinc serta kandungan mineral yang lainnya(10) Kepadatan tulang seorang wanita usia subur tidak memiliki hubungan bermakna dengan jumlah paritas, umur dan IMT (Indeks massa tubuh) ibu(11). Sedangkan pada proporsi berat badan wanita usia subur ditemukan sebanyak $41,6 \%$ tidak dipengaruhi oleh lama penggunaan alat kontrasepsi hormonal $(12,13)$. Tulang merupakan jaringan dapat berubahubah dan memiliki sistem regenerasi seluler yang kompleks. Sel-sel lama dirubah selanjutnya diganti dengan sel-sel baru(14,15) Keseimbangan dalam resorpsi dan formasi tulang tersebut menentukan densitasnya dan memengaruhi kerentanan seseorang terhadap fraktur(16)

Kelompok usia 30 sampai 50 tahun sebagai akseptor kb hormonal tidak didapatkan hubungan dengan kadar massa tulang atau tanda pengeroposan tulang(17), hal ini dipengaruhi oleh kurangnya asupan vitamin dan aktivitas fisik dari tiap individu yakni wanita usia subur.

Adapun keterbatasan dalam penelitan ini adalah: penelitian dilaksanakan pada masa pandemi covid-19 sehingga jumlah responden terbatas dikarenakan terbatasnya atau berkurangnya jumlah kunjungan akseptor di poli KB.

\section{KESIMPULAN DAN SARAN}

Lama penggunaan kontrasepsi hormonal tidak berhubungan dengan kadar massa tulang ibu akseptor $\mathrm{kb}$ hormonal. Diharapkan untuk peneliti selanjutnya untuk melihat aktivtas fisik ibu apakah berhubungan dengan kadar massa tulang ibu sebagai akseptor kb hormonal.

\section{UCAPAN TERIMA KASIH}

Terima kasih kami ucapkan kepada pihak institusi dalam hal ini LPPM Universitas Megarezky yang telah membantu, tempat penelitian dan para responden yang telah bersedia mengikuti penelitian ini serta kepada kementerian riset dan tekhnologi yang telah memberikan bantuan dana penelitian kepada kami

\section{DAFTAR PUSTAKA}

1. Setyowati A, Nuraisya W, Purwandari ES. The Effect Of Long-Term Contraception Of Contraception Against Bone Density Levels Anis. Jurnal Ilmiah Kebidanan. 2018;4(2):120-4.

2. Risnawati, Nasruddin WN. Concentration Of Calcium Acceptor Injective Depomedroxion Of Acetate Progesteron With Combination Of Perimenopause Women. Jurnal Life Birth. 2020;4(1):36-43.

3. Chowdhury B, Kundu B. Body Mass Index can be a Good Predictor of Bone Mineral Density in Postmenopausal Women in India. International Journal of Public Health Science (IJPHS). 2014;3(4):276.

4. Simanjuntak NM, Yerizel E. 1,25 Dihydroxyvitamin D dan kalsium pada akseptor depot medroxyprogesteron asetat ( DMPA ) berdasarkan lama pemakaian. Jurnal Gizi Klinik Indonesia. 2018;15(2):52-8.

5. Ruseno CJ, Rahayuningsih HM. Status Kepadatan Tulang Berdasarkan Kategori Lingkar Pinggang Wanita Dewasa. Journal of Nutrition College. 2015;4(4):350-7.

6. Sugiyono. Metode Penelitian Kuantitatif, Kualitatif, dan R\&D. 2nd ed. Sutopo, editor. Bandung: Alfabeta; 2019.

7. Peni EM, Pipit cahyani TI. Lama Pemakaian KB Suntik DMPA dan densitas Tulang. Kebidanan. 2015;1(1):34-41.

8. Rahayu Eryanti. K, Nurqalbi Sampara JS. The Effect of Using Family Planning Illustration Videos on Knowledge of Family Planning Acceptors as an Effort to Prevent Baby Booms during the Covid -19 Pandemic. Poltekita: 
Jurnal Ilmu Kesehatan. 2021;15(3):223-8.

9. Rahmawati NMA, Andarjati R, Supardi S. Perbandingan Penggunaan Kontrasepsi Suntik Zat Tunggal Dan Kombinasinya Terhadap Kejadian Reaksi Obat Yang Tidak Dikehendaki Di Satu Bidan Praktek Kota Depok. Jurnal Kefarmasian Indonesia. 2017;7(1):46-54.

10. Herowati D, Sugiharto M. Hubungan Antara Kemampuan Reproduksi, Kepemilikan Anak, Tempat Tinggal, Pendidikan Dan Status Bekerja Pada Wanita Sudah Menikah Dengan Pemakaian Kontrasepsi Hormonal Di Indonesia Tahun 2017. Buletin Penelitian Sistem Kesehatan. 2019;22(2):91-8.

11. Sudirman J, Sampara N, Mawang S, Passe R, Aswan R, Ahmad M. The analysis of reducing blood glucose levels of diabetics with diabetes mellitus by giving a secang wood stew (Caesalpinia sappan L.) to menopausal women in Makassar City. Enfermeria Clinica. 2020;30:506-9.

12. Sihombing I, Wangko S, Kalangi SJR. Peran Estrogen Pada Remodeling Tulang. Jurnal Biomedik (Jbm). 2012;4(3):18-28.

13. Fitriana N, Rosyidah I. Pengembangan penyuluhan kesehatan meningkatkan pemakaian alat kontrasepsi di puskesmas Purwoyoso kota Semarang. Jurnal Riset Kebidanan Indonesia. 2021;4(2):77-83.

14. Nyaradzo M. Mgodi, Cliff Kelly BG. Factors associated with bone mineral density in healthy African women. HHS Public Access. 2015;10(1):1-17.

15. Martanti LE, Hesti KY, Laska Y. Hubungan Faktor Risiko Umur, Indeks Massa Tubuh, Kebiasaan Olahraga Dan Konsumsi Kafein Dengan Gejala Osteoporosis Pada Akseptor Kb Dmpa Di Wilayah Puskesmas Tengaran. Jurnal Kebidanan. 2018;8(1):22.

16. Goshtasebi A, Subotic Brajic T, Scholes D, Beres Lederer Goldberg T, Berenson A, Prior JC. Adolescent use of combined hormonal contraception and peak bone mineral density accrual: A meta-analysis of international prospective controlled studies. Clinical Endocrinology. 2019;90(4):517-24.

17. Sudirman J, Sinrang AW, Marwang S, Nurlaily A, Sabar S, Astuti AT, et al. The analysis estradiol levels against sexual desire in perimenopause women in Makassar, South Sulawesi, Indonesia. Enfermeria Clinica. 2020;30:350-3. 